\title{
Measurement of Urban-Rural Integration Level in Suburbs and Exurbs of Big Cities Based on Land-Use Change in Inland China: Chengdu
}

\author{
Meimei Wang ${ }^{1}$, Yongchun Yang ${ }^{1, *}$ and Tao Guo ${ }^{2}$ (D) \\ 1 School of Resource and Environmental Science, Lanzhou University, Lanzhou 730000, China; \\ wangmm@lzu.edu.cn \\ 2 Institute of Remote Sensing and Digital Agriculture, Sichuan Academy of Agricultural Sciences, \\ Chengdu 610066, China; guotao3s@163.com \\ * Correspondence: yangych@lzu.edu.cn
}

Citation: Wang, M.; Yang, Y.; Guo, T. Measurement of Urban-Rural Integration Level in Suburbs and Exurbs of Big Cities Based on Land-Use Change in Inland China: Chengdu. Land 2021, 10, 474

https://doi.org/10.3390/land10050474

Academic Editor: Thomas W. Sanchez

Received: 15 March 2021

Accepted: 29 April 2021

Published: 1 May 2021

Publisher's Note: MDPI stays neutral with regard to jurisdictional claims in published maps and institutional affiliations.

Copyright: (c) 2021 by the authors. Licensee MDPI, Basel, Switzerland. This article is an open access article distributed under the terms and conditions of the Creative Commons Attribution (CC BY) license (https:// creativecommons.org/licenses/by/ $4.0 /)$.

\begin{abstract}
Urban growth and development can be interpreted as a combined process of "urban spillover" and "local urban sprawl", from overall urban-rural development to urban-rural integration (URI). The process of suburban development in western China is a complex system, which reflects the characteristics of industrialization and urbanization in western China. Chengdu is the most representative of the big cities for economic and social structure change in western China. To analyze the changes on URI degree based on the built-up land change, and to explore the practical URI paths in both the suburbs and exurbs of Chengdu, we use land-use remote-sensing monitoring data from 2000, 2005, 2010, and 2015 in this paper, whereafter URI indexes are built from space, economy, and society. The land-use change of the suburbs and exurbs of Chengdu from 2000 to 2015 are analyzed by ArcGIS. Results indicate that the biggest growth part of built-up land is other built-up land, followed by commercial/industrial land, and the last is residential land. The built-up land spreads quickly from 2000 to 2005, and shows distinct separation characteristics in the suburbs of Chengdu. It is relatively slow in the exurbs. Moreover, built-up land connects better in the suburbs than in the exurbs. Based on the change of built-up land in Chengdu from 2000 to 2015, spatial integration data are calculated, economic integration and social integration data are chosen from statistics, and the change of URI levels in the suburbs and exurbs of Chengdu is calculated. The results show that first, economic integration and social integration have great influence on URI, and their effects are increasing. The significance of spatial integration in URI has gradually reduced. Second, URI levels in counties of the suburbs and exurbs of Chengdu rose from 2000 to 2015, more highly in the suburbs than in the exurbs. URI in counties of the exurbs showed a marked difference. URI in the southeast counties of the exurbs is generally high. The foundation of URI is weaker in the counties and districts in the southwest counties of the exurbs in Chengdu, but it is growing steadily in URI, and the northern counties in the exurbs of Chengdu are in the process of rapid URI. The paths of URI in the suburbs and exurbs in Chengdu can be roughly divided into an industry-developing model in the suburbs, service-industry-developing model in the suburbs, agriculture-developing model in the exurbs, service-industry-developing model in the exurbs and infrastructure-developing model in the exurbs.
\end{abstract}

Keywords: built-up land; urban-rural integration (URI), URI level; land-use change; path; Chengdu

\section{Introduction}

With continuous progress of globalization and urbanization, both developed and developing countries have explored countermeasures that suit their national conditions, to promote sustainable development [1]. After industrialization and urbanization, the United States paid attention to rural construction to solve "urban disease" in urban areas, which 
effectively improved production and living conditions in rural areas, and promoted urbanrural integration (URI) [2]. Europe began to develop small towns in the late 20th century, which improved URI [3]. Since the reform and opening up in 1978, when industrialization and urbanization began to develop rapidly in China, an imbalance between urban and rural areas has appeared, which has resulted not only in identity disparity, but also in an imbalance in interest distribution and redistribution. This is the root of many of China's development problems [4]. Thus, China has made arduous explorations and efforts to eliminate the urban-rural dual structure. The reform and opening up in 1978 can be seen as the turning point. The relationship between urban and rural areas in China shows distinct evolution characteristics in two successive stages.

From 1949 to 1978, agriculture provided capital accumulation for industrial development to achieve industrialization. After 1978, the Chinese government adopted a comparative advantage strategy, where a traditional planning economy turned to a modern market economy. In this process of transformation, the dual urban-rural system has been gradually disintegrated, and the urban-rural relationship adjustment has become an important force in China's social and economic development [5]. After the new normal of China's economic and social development, the urban-rural relationship entered a period of integrated development. The 17th National Congress of the Communist Party of China (CPC) in 2007 proposed overall urban-rural development, and the 19th National Congress of the CPC in 2017 put forward rural revitalization and regional coordinated development strategies. The central document of the China State Council made a proposal to establish and perfect the development mechanisms and policy systems of URI, which indicated that urban and rural areas are an organic whole, and resource elements in towns and villages can flow between each other [6].

Sociologists and anthropologists consider URI to be the close combination of urban and rural economy and society, based on the premise of breaking the regional partition barrier [7-9]. Economists believe that URI should be reflected in allocation and the optimal comprehensive benefit of urban and rural productivity [10]. URI is emphasized at a high level in the benign balance system of the regional ecological economy, in ecology [11]. From the definition of sustainable development, geographers suggest that URI is the reasonable connection of space partition [12]. They believe that URI is a spatial extension, from economy to society, economy, and environment [13]. Meanwhile, it is not only the process of rural revitalization, but also a step to balance the development of population, resources, and environment [14]. The connotation of URI in existing research is multidimensional, and refers to space, society, economy, ecology, and culture [15]. The concept of URI is seldom studied in the West, where most studies focus on the social, economic, cultural, and political connections between cities and villages [16]. Existing research generally selects space, economy, society, and the ecological environment to construct an evaluation index system of URI. Indicators of URI can be roughly divided into economic development, infrastructure, public services, residential life, and spatial connectivity [17]. The identification of URI and the rural complex can reflect the degree of URI $[18,19]$. As for the evaluation methods, global principal component analysis (GPCA) and horizontal and vertical stretch grade method are the most used.

With the advancement of URI research, several models and theories have been put forward to analyze urban-rural links in developing countries, such as the model of urbanrural unified design [20], regional network model [21], and the theory of the urban-rural continuum [22] and urban and rural partnerships [23]. Based on these models and theories, the following typical patterns of URI have been found. First, the country melts into the city pattern: for villages in the city and on the urban fringe, land has great potential for appreciation, the amount of non-agricultural employment is highest, and farmland has or will change to non-agricultural built-up land [24]. With the help of the city's drive and radiation, residents can enjoy the same social security benefits, infrastructure, and basic public services as urban residents, without much government investment [25]. It is relatively easy to reach URI in this area. Second, the urban-rural interaction pattern: 
for counties in economically developed areas and suburbs of big cities, non-agricultural employment is higher, with urban radiation, which has good conditions for the exchange of urban and rural elements. Social capital can be attracted to the rural construction and development in such areas; the government is supposed to only give policy support, not money [26]. It is moderately difficult to reach URI in this area. Third, city-promotescountryside pattern: for counties in economically underdeveloped areas and exurbs of big cities, non-agricultural employment is lower, and the internal impetus for achieving sustained development is feeble, so the exchange of urban and rural elements is inaccessible. The government is expected to use administrative means to promote urban elements to the countryside, and it is hard to reach URI in this area.

The existing literature tends to distinguish "cities" from "suburbs" by counting population [27] and distance from the center [28]. Suburbs are urbanized areas that contain a very populous city, excluding the population of that populous city. Exurbs are the areas outside of urbanized areas containing the very populous city [29]. Land is the space carrier of a population's main social and economic activities [30]. Many social and economic problems in urban and rural development can be shown through land use [31]. Built-up land is the main body of land use [32]. Thus, land use and development intensity of built-up land use have transitional properties, from the suburbs to the exurbs [33]. Simultaneously, built-up land-use status affects the process of URI [34]. Via the radiation and driving force of the city, land use in the suburbs and exurbs shows significant geographical variation [35]. The impact of the city is more acute in land use in the suburbs [36] - especially built-up land [37], followed by agricultural land. The impact of the city is mild on land use in the exurbs, where land-use structure changes slowly [38]. Together, the shape of built-up land use is intricate [39]. This is very common in the suburbs of large cities in mainland China.

The forming process of built-up land use of the suburbs is directly affected by the city [40], which shows urban and suburban interaction [41]. Most of the built-up area in rapidly developing cities, especially in regions where local urban sprawl is interwoven with urban spillover, consists of industrial land and residential land, which often account for more than $25 \%$ and $35 \%$ of the total area, respectively [42]. However, various types of builtup land use of suburbs have not been well documented and analyzed. In Chinese cities, where built-up areas usually extend across traditional urban and rural territories, urban growth and development can be interpreted as a combined process of "urban spillover" and "local urban sprawl" [43,44]. In the process of the built-up area crossing the traditional urban and rural areas, there are two forces to promote built-up land changes. The former refers to the extension of government-driven infrastructure to rural areas to promote urban development, the latter refers to scattered development by rural households, towns, and villages. As the built-up land changes, it is manifested as the change of commercial and industrial land, residential land, and other built-up land, in terms of space. Meanwhile, the life mode and production system of local residents have also changed accordingly, followed by the change in resident income and occupation, and industry proportion [45]. As land use and economic levels change, the social life of the inhabitants changes accordingly [46]. The specific changes include population migration, external communication, medical care, etc. It is not difficult to discover that land-use change promotes URI in counties situated around a metropolis. Furthermore, URI shows a difference between exurbs and suburbs.

There were 600 million farmers in mainland China in 2015, which accounted for $41.48 \%$ of the total population. In addition, 16.6 million people were in the rural poor population in 2018, and poverty incidence was 1.7\% (http:/ / www.stats.gov.cn/ accessed on 6 December 2020). China's current national conditions show a high proportion of the rural population, a poor economic foundation, and a large gap between urban and rural areas. To reduce this gap, China has implemented macro strategies, such as overall urban-rural development, new rural construction, unifying the design between the city and the countryside, and new-type urbanization. However, the effect of URI has not done well, and is still in the exploratory stage. Chengdu is located in the western Sichuan plain, and is a typical big city in western China, so it can be viewed as a microcosm of Chinese economy and society. 
Chengdu was officially approved by the central government as one of the first national experimental units of overall urban-rural development in 2007. Through the promotion of the large-scale pharmaceutical industry and the industrialization of agriculture, and reforming the census register system, the gap between urban and rural areas is narrowing, and URI has increased. Thus, a pattern where the big city drives the big countryside has formed, which is known as the "Chengdu Phenomenon". Therefore, Chengdu is a typical case of URI in China. This paper chooses Chengdu as the research area, and tries to answer the following questions: First, what is the difference in land-use changes in the suburbs and exurbs of Chengdu? Second, what are the changes on URI degree based on the land-use change? Third, what are the practical URI paths in the suburbs and exurbs of Chengdu?

\section{Research Area and Methods}

\subsection{Research Area}

The Outline of the National Comprehensive Three-dimensional Transport Network Plan (ONCTTNP) of 2021 identified the Beijing-Tianjin-Hebei, Yangtze River Delta, Guangdong-Hong Kong-Macao Greater Bay Area and Chengdu-Chongqing economic circle as four "poles", around which to build clusters of international comprehensive transport hubs. Thus, Chengdu-Chongqing has been officially recognized as the "fourth pole" in China's development landscape.

Chengdu is a megacity in the west of China, and it is also a center of transportation and communication, technology, finance, and modern logistics in southwest China. Like all big cities in China, Chengdu is facing a huge urban-rural gap in economic and social development. The central zone in Chengdu is mainly modernized cityscape, but the suburbs and exurbs comprise a decaying rural landscape, where agricultural population makes up $45 \%$ of the population. Thus, URI faces serious resistance in Chengdu. Under such conditions, Chengdu launched its overall urban-rural development in 2003, to narrow the widening gap between rural and urban areas. In addition, it was officially approved as one of the first national experimental units of overall urban-rural development in 2007. From 2010, Chengdu implemented the policy of URI. After more than 10 years of exploration and development, resident income and living environment have improved significantly in the suburbs and exurbs areas. Meanwhile, the urban-rural gap in Chengdu has maintained a continuous downward trend, known as the Chengdu Phenomenon. In December 2019, Chengdu was designated as a national pilot area for urban-rural integrated development.

According to the population and the district of Chengdu, counties of Chengdu can be divided into the central zone, suburbs, and exurbs (http:/ /www.chengdu.gov.cn/ accessed on 6 December 2020). The central zone includes the districts of Qingyang, Jinjiang, Wuhou, Chenghua, and the high-tech district; the suburbs are the districts of Xindu, Longquanyi, Wenjiang, Pidu, and Shuangliu; and the exurbs are Qingbaijiang district, the counties of Jintang, Pujiang, Xinjin, Dayi, and the cities of Dujiangyan, Pengzhou, Chongzhou, and Qionglai. The research areas in this paper are the 14 counties in the suburbs and exurbs; see Figure 1.

\subsection{Data Sources and Classification Criteria}

Land-use data released by the Institute of Geographical Sciences and Resources of the Chinese Academy of Sciences (http:/ / www.resdc.cn/ accessed on 6 December 2020) is used in this paper. Based on the land-use remote-sensing monitoring data $(30 \mathrm{~m})$ in 2000, 2005, 2010, and 2015, land classification information is extracted by ERDAS 9.2 and ArcGIS 10.2.

Built-up land usually consists of parcels associated with primary land use, such as commercial, residential, industrial, and transportation [47,48]. According to the built-up land-planning standards by the Ministry of Housing and Urban-Rural Development (MOHURD) of the People's Republic of China in 2014, the classification of built-up land in this paper includes commercial and industrial land, residential land, and other built-up land. 


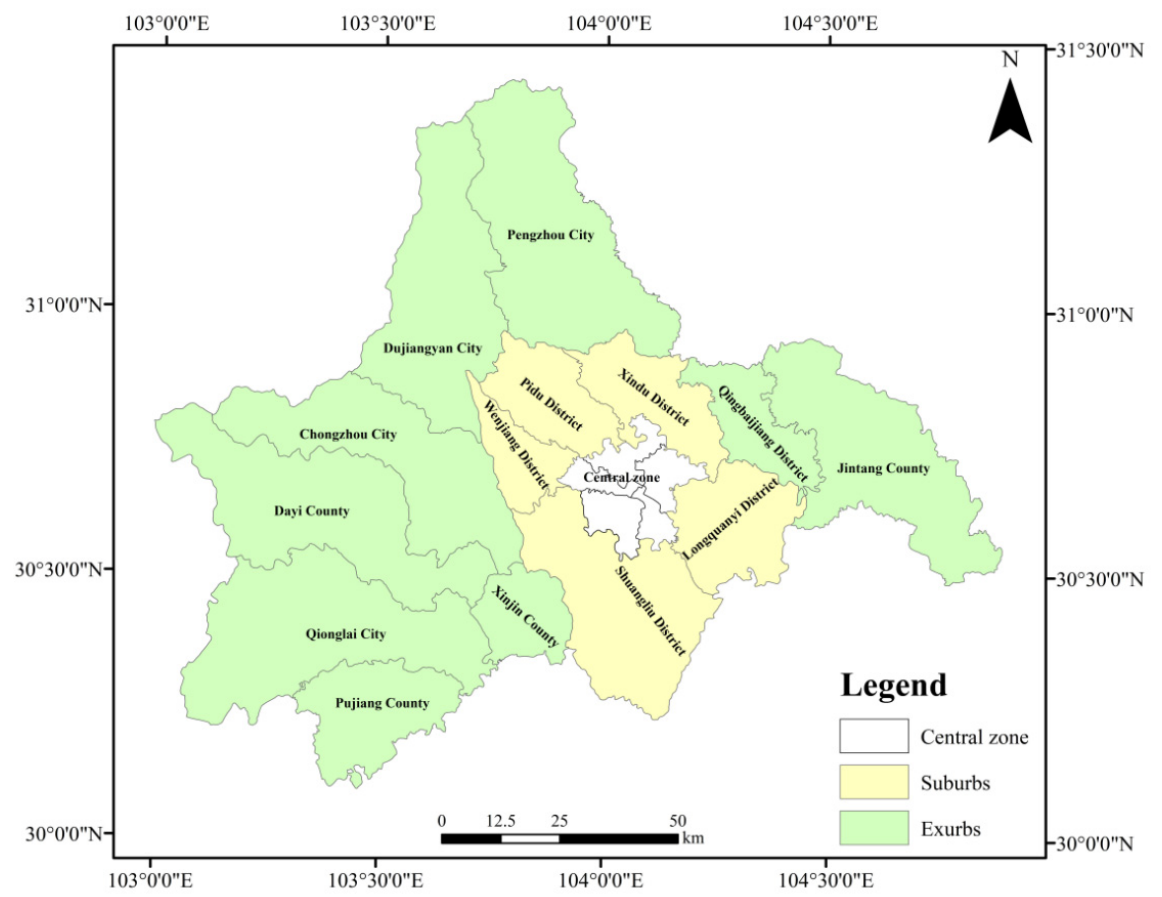

Figure 1. County districts in the suburbs and exurbs of Chengdu.

\subsection{Research Method}

(1) Boltzmann entropy

Entropy is related to the degree of disorder in a system. As disorder increases, entropy increases, so entropy can be thought of as a measure of disorder of a system. Boltzmann entropy is a measure of the disorder of a thermodynamic system, expressed by two concepts, namely the macrostate and the microscopic state [49]. Boltzmann entropy here is used to show in the system the fuzzy degree of built-up land in the suburbs and exurbs of Chengdu.

$$
S=k \ln W
$$

where $\mathrm{K}$ is the Boltzmann constant $(=1.38 \times 10-23 \mathrm{~J} / \mathrm{K}[49])$, and $W$ is the number of microstates compatible with some macroscopic parameters.

(2) The perimeter area fractal dimension (PAFRAC)

The fractal dimension shows the complexity of city boundary shapes. It can reflect the change of land-use shape and land-use disturbance degree [50]. The fractal dimension in this paper describes the spatial morphologic change, by describing the expansion mode of built-up land in the suburbs and exurbs of Chengdu.

$$
\text { PAFRAC }=\frac{2 /\left[n_{i} \sum_{j=1}^{n}\left(\ln p_{i j} \times \ln a_{i j}\right)\right]-\left[\left(\sum_{j=1}^{n} \ln p_{i j}\right)\left(\sum_{j=1}^{n} \ln a_{i j}\right)\right]}{\left(n_{i} \sum_{j=1}^{n} \ln p_{i j}^{2}\right)-\left(\sum_{j=1}^{n} \ln p_{i j}\right)^{2}}
$$

where $a_{i j}$ is the area of plaque $i j, p_{i j}$ is the perimeter of plaque $i j$, and $n_{i}$ is number of plaque $i$ in survey region.

(3) The contagion degree (CONTAG)

The value of the CONTAG describes the aggregation degree of different plaque classes in the area, based on the adjacency relationship between plaque types [50]. CONTAG here is used to show the dispersion degree of built-up land in suburbs and exurbs of Chengdu.

$$
\text { CONTAG }=\left[1+\frac{\sum_{i=1}^{m} \sum_{k=1}^{m}\left[\left(P_{i}\right)\left(\frac{g_{i k}}{\sum_{k=1}^{m} g_{i k}}\right)\right]\left[\ln \left(P_{i}\right)\left(\frac{g_{i k}}{\sum_{k=1}^{m} g_{i k}}\right)\right]}{2 \ln (m)}\right]
$$


where $P_{i}$ is the area percentage of plaque $i, g_{i k}$ is number of adjacent plaques of plaque $i$ and plaque $k$, and $m$ is the total number of plaques in the landscape.

(4) Cohesion index (COHESION)

Cohesion index can show the natural state connectivity of corresponding plaque types [50]. It is chosen here to reflect the connectivity and stability of built-up land in the suburbs and exurbs of Chengdu.

$$
\text { COHESION }=\left[1-\frac{\sum_{i=1}^{m} \sum_{j=1}^{n} p_{i j}}{\sum_{i=1}^{m} \sum_{j=1}^{n} p_{i j} \sqrt{a_{i j}}}\right] \times\left[1-\frac{1}{\sqrt{A}}\right]^{-1} \times 100
$$

where $p_{i j}$ is the perimeter of plaque $i j$ in grid form, $a_{i j}$ is the acreage of plaque $i j$ in grid form, and $A$ is the total number of grids in the landscape.

\section{The Land-Use Change of the Suburbs and Exurbs of Chengdu}

\subsection{The Land-Use Change from 2000 to 2015}

The land-use change of the suburbs and exurbs of Chengdu from 2000 to 2015 is shown in Figure 2. Results show that planted cropland in the suburbs and exurbs of Chengdu are in decline, and that built-up land and forest are increasing. Among them, the increase of built-up land is most obvious-its increase amplitudes exceed $100 \%$ in Longquanyi, Qingbaijiang, and Pidu.
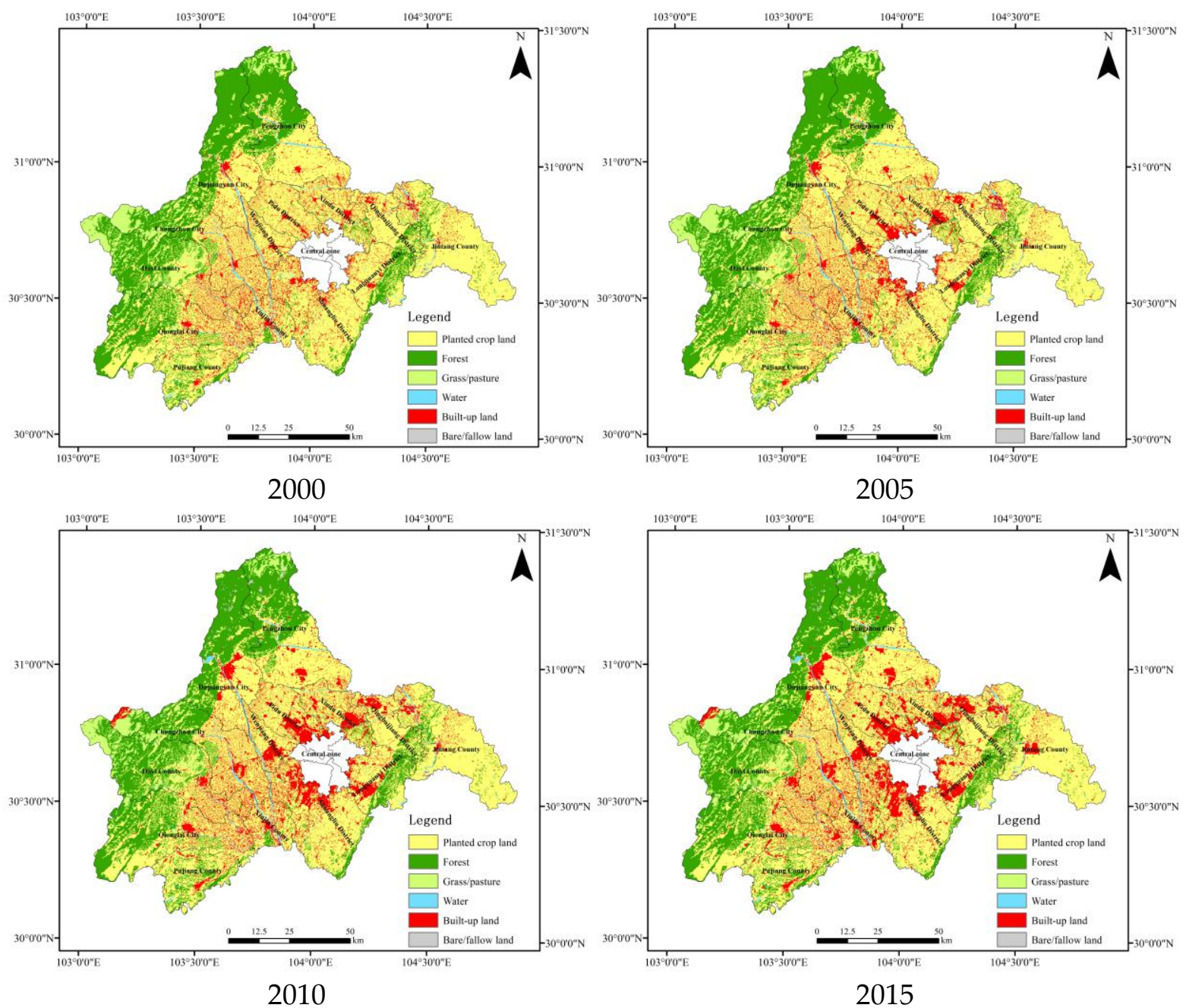

Figure 2. The land-use change of the suburbs and exurbs of Chengdu from 2000 to 2015. 


\subsection{The Change in Built-Up Land in the Suburbs and Exurbs of Chengdu from 2000 to 2015}

Since the spatial state of URI can be directly reflected by the change in built-up land, the change in built-up land in suburbs and exurbs of Chengdu from 2000 to 2015 is analyzed, the result is shown in Figure 3. From 2000 to 2015, first, the biggest growth is other built-up land, followed by commercial/industrial land, and the last is residential land. Second, other built-up land and commercial/industrial land are growing rapidly in most counties, especially in Qingbaijiang and Pidu. Third, residential land is withered, even shrinking.
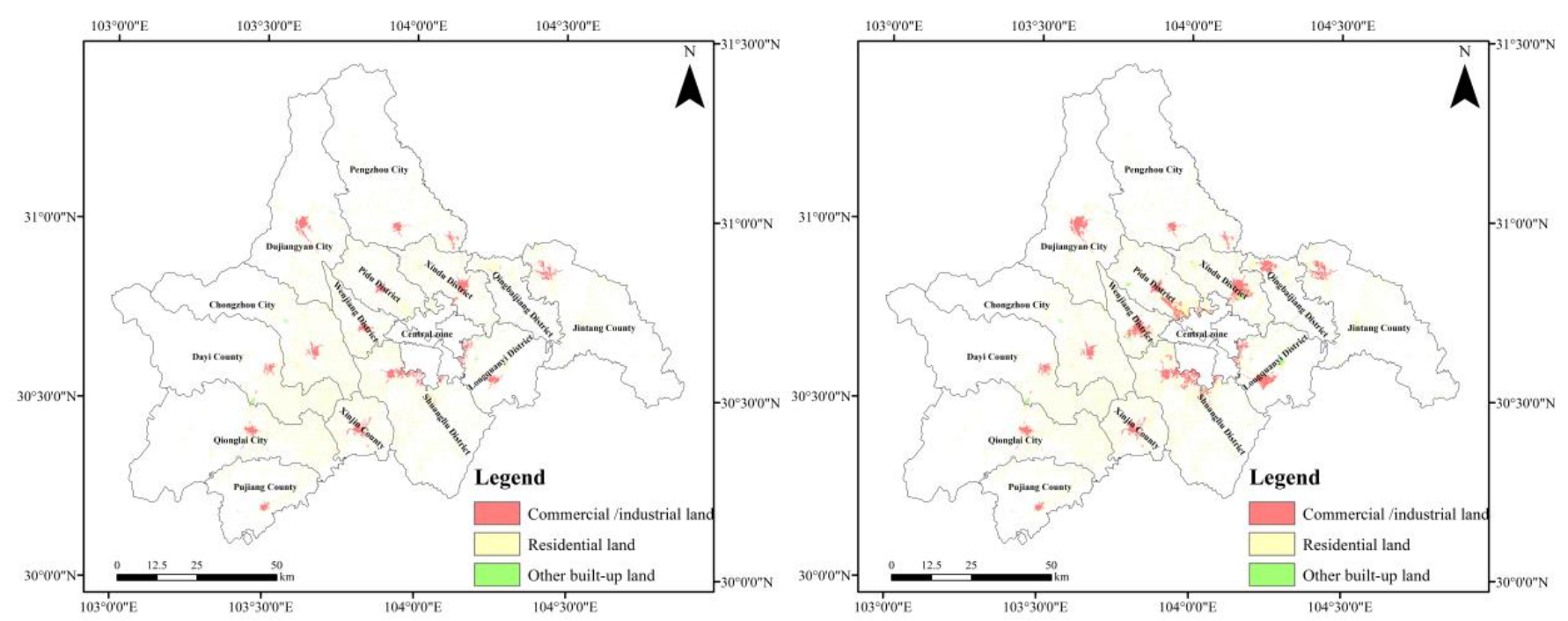

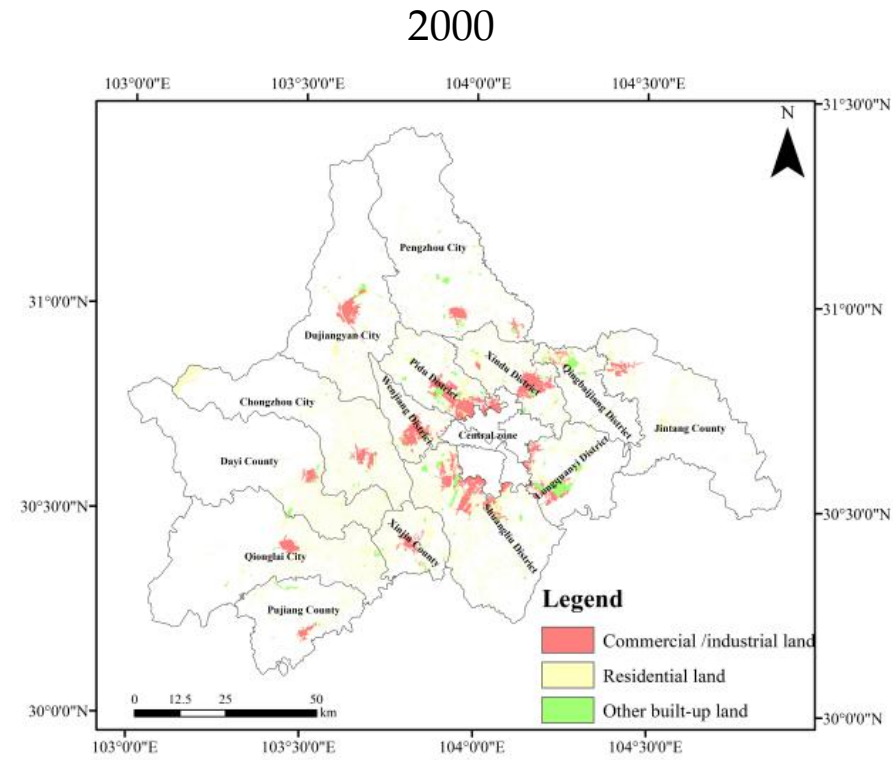

2010

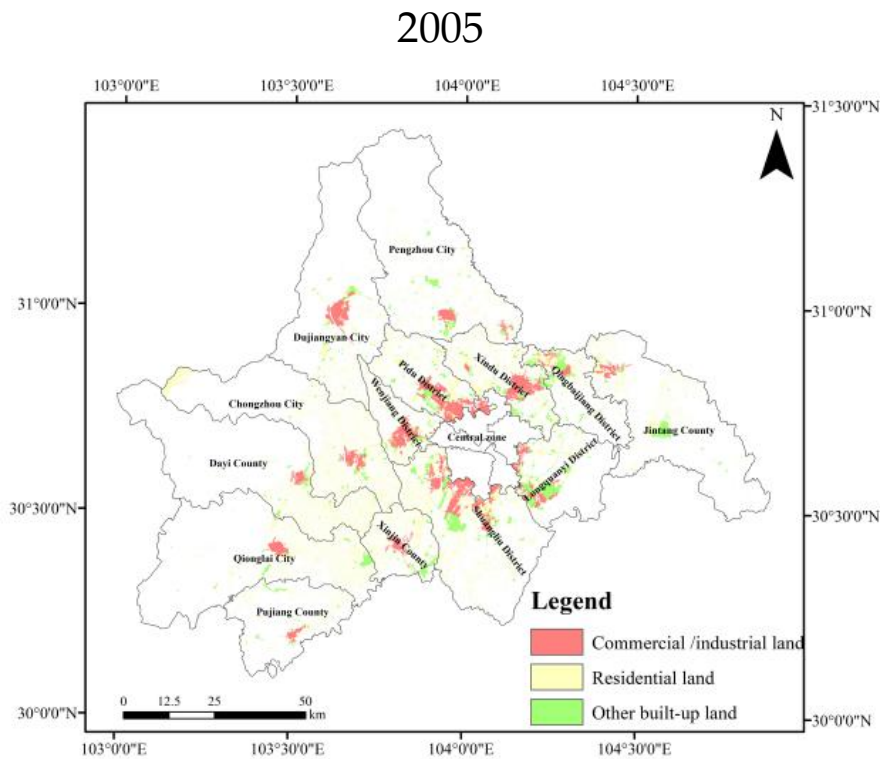

2015

Figure 3. The change in built-up land in the suburbs and exurbs of Chengdu from 2000 to 2015.

Boltzmann entropy, the perimeter area fractal dimension (PAFRAC), the contagion degree (CONTAG) and the cohesion index (COHESION) are used to reflect the mutual integration degree of different types of built-up lands in counties of Chengdu.

(1) Boltzmann entropy of built-up land

From 2000 to 2015, Boltzmann entropy of built-up land in the counties of the suburbs and exurbs of Chengdu are rising, more so in the suburbs than in the exurbs, and most obviously is Longquanyi. 
Boltzmann entropy of built-up land in the suburbs is generally higher than that in exurbs. This means that the boundary between the three types of built-up land is fuzzier [51], the three types of built-up land show a more closely integrated state, and the integration is growing; see Figure 4.

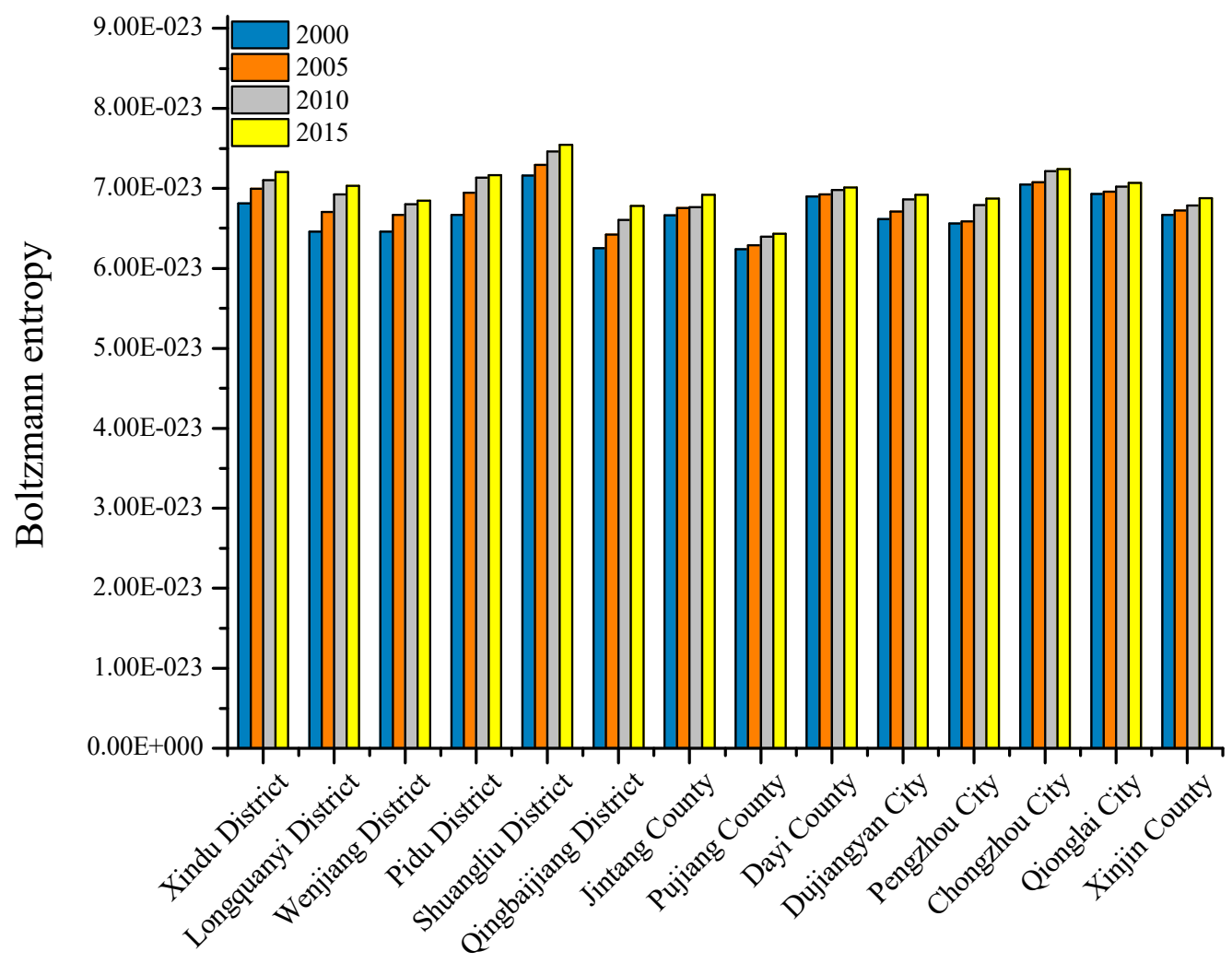

Figure 4. The Boltzmann entropy of built-up land from 2000 to 2015.

(2) The PAFRAC of built-up land

From 2000 to 2015, the PAFRAC of built-up land in the suburbs and exurbs of Chengdu are reduced (Figure 5). Meanwhile, the PAFRAC in the exurbs are more obvious than that in suburbs. It shows that built-up land in the suburbs and exurbs of Chengdu is increasing by outside expansion and internal adjustment. The built-up land spread quickly from 2000 to 2005; after that, the built-up land increased by internal adjustment. In general, the spatial pattern of built-up land is simple in Dayi and Pujiang, and is relatively intricate in Qingbaijiang and Jintang.

(3) The CONTAG of built-up land

From 2000 to 2015, the CONTAG of built-up land in the suburbs and exurbs of Chengdu have reduced (Figure 6), i.e., the degree of fragmentation in built-up land has increased by years. The downward trend of the CONTAG of built-up land in the suburbs is lower, which indicates that the degree of fragmentation in the suburbs is higher. Meanwhile, the values of CONTAG are smaller, i.e., commercial/industrial land, residential lands, and other built-up land show more distinct separation characteristics, in the suburbs of Chengdu; among the counties, the separation characteristics are more distinct in Xindu, Longquanyi, and Pidu. The values of CONTAG are larger generally in the exurbs; among the counties, they are larger in Pujiang, Dujiangyan, and Pengzhou, which shows that the separation of commercial/industrial land, residential land, and other built-up land is not obvious, and that the development of built-up land is relatively slow in the exurbs of Chengdu. 


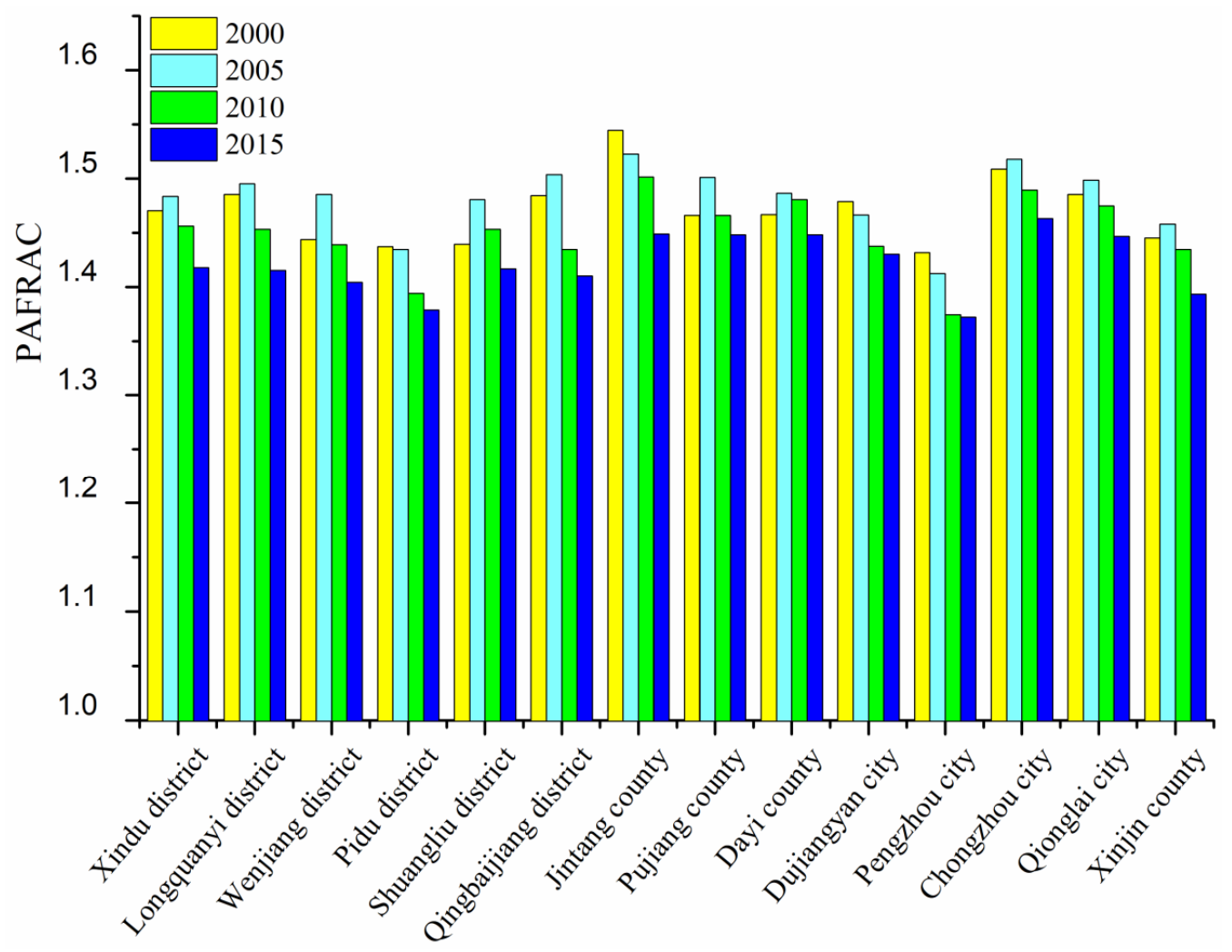

Figure 5. The PAFRAC of built-up land from 2000 to 2015.

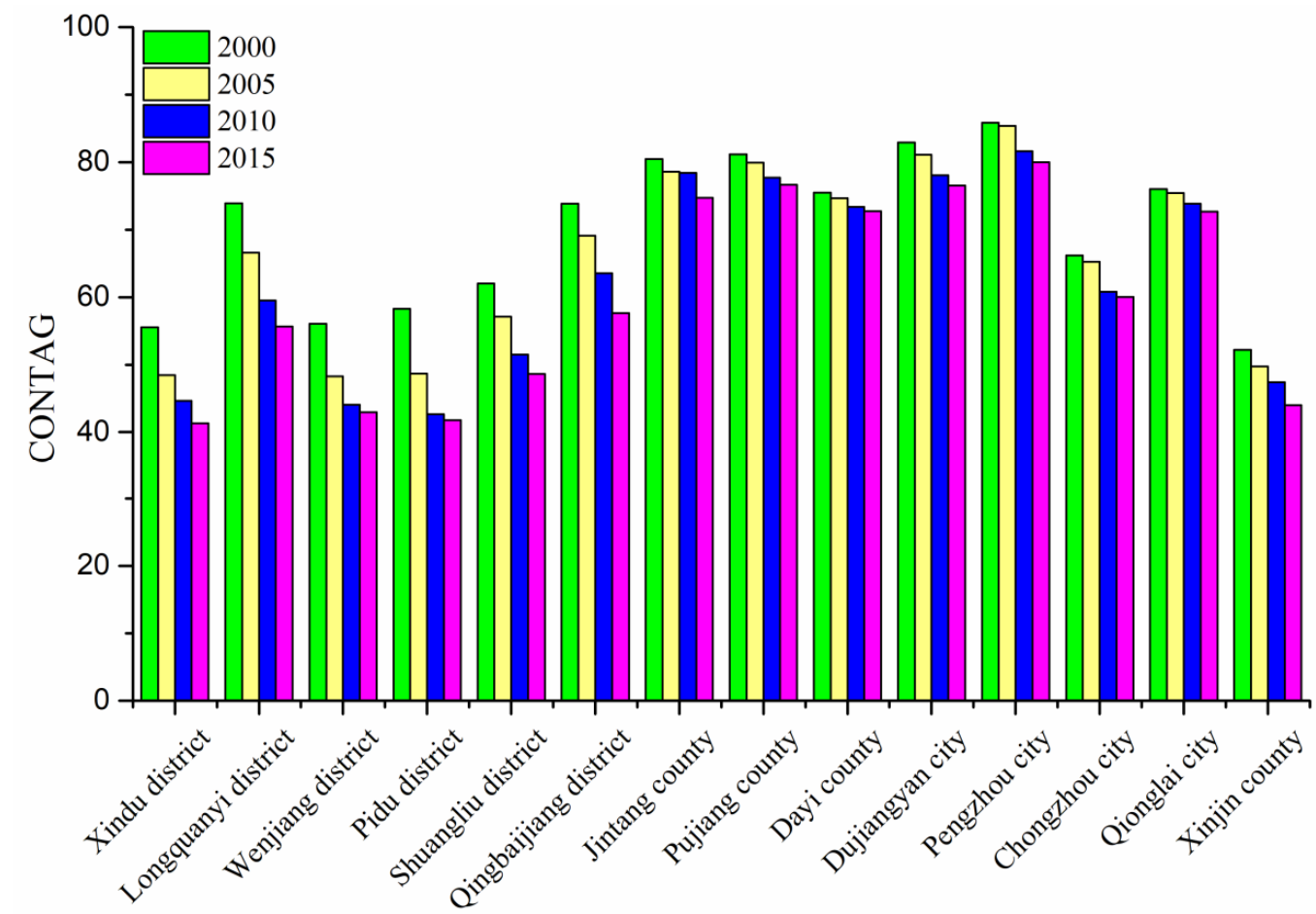

Figure 6. The CONTAG of built-up land from 2000 to 2015.

(4) The COHESION of built-up land

From 2000 to 2015, there is a growing trend showing that the COHESION of builtup land in the suburbs and exurbs of Chengdu is reduced (Figure 7). The cohesion indexes remain between 90 and 100, and mean built-up land in those counties has good connectivity and stability. Relatively, the COHESION values in the suburbs are higher and 
are growing faster, meaning that commercial/industrial land, residential land, and other built-up land is better connected in the suburbs. Among them, the COHESION values are higher in Longquanyi and Shuangliu. They are lower and grow more slowly in the exurbs, specifically in Dujiangyan and Qionglai, and they are lower in Dayi and Qionglai.

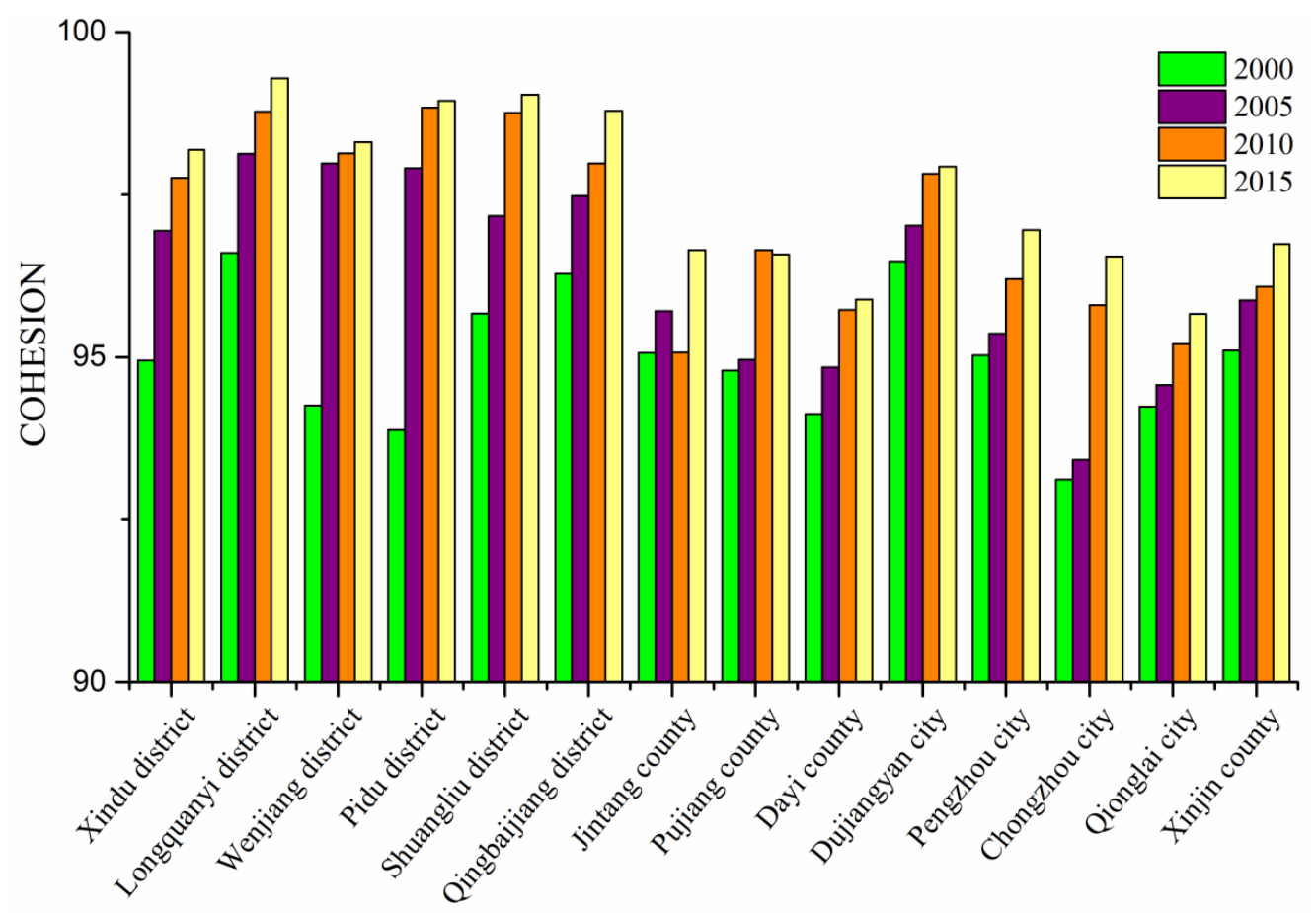

Figure 7. The COHESION of built-up land from 2000 to 2015.

Boltzmann entropy shows the system stats [52]; it can reflect the fuzzy degree of three types of built-up land. The larger Boltzmann entropy indicates the system is fuzzier, and research shows that Boltzmann entropy of built-up land in the suburbs generally higher, which means that the boundary between three types of built-up land in the suburbs is fuzzier than that in the exurbs, i.e., the three types of built-up land are more integrated in the suburbs. PAFRAC shows the complexity of city boundary shapes; it can reflect the change of land-use shape and disturbance degree [53]. The larger PAFRAC indicates built-up land expanding faster, and research shows that PAFRAC in the exurbs is more obvious than that in the suburbs, i.e., built-up land spread is based on outward expansion in the exurbs. If CONTAG is lower, the degree of land fragmentation is higher [53]; research shows that CONTAG of built-up land in suburbs is lower, which indicates fragmentation in the suburbs is higher than in the exurbs. When the COHESION value is higher, built-up land in those counties has good connectivity and stability [53]; research shows the COHESION value is higher in the suburbs than in the exurbs, meaning commercial/industrial land, residential land, and other built-up land is becoming integral to in the space. To sum up, it is not difficult to understand that the three types of built-up land tend to be integrated into space in the suburbs. Meanwhile, this trend of integration is reflected in the exurbs of Chengdu, but just more slowly.

\section{URI Level Change Based on Land-Use Change}

\subsection{The URI Indexes}

Combined with the purpose of this study and existing research, the URI indicator system in this paper is built from economic integration, social integration, and spatial integration (Table 1). Via quantitative study, the change of URI from 2000 to 2015 is analyzed. 
Table 1. The URI indicator system.

\begin{tabular}{|c|c|c|}
\hline Goal Level & Subsystem Level & Index Level \\
\hline URI level & Economic integration & $\begin{array}{c}\text { Per-capita disposable income of households } \\
\text { (yuan/person) } \\
\text { The proportion of primary industry in GDP (\%) } \\
\text { The proportion of secondary industry in GDP (\%) } \\
\text { The proportion of tertiary industry in GDP }(\%) \\
\text { Percentage of non-agricultural population }(\%) \\
\text { Engel coefficient } \\
\left.\text { Population density (person } / \mathrm{km}^{2}\right) \\
\text { Population migration rate }(\%) \\
\text { Rotation volume of goods transport (billion ton } / \mathrm{km}) \\
\text { Volume of passenger traffic (billion } / \mathrm{km}) \\
\text { Per-capita post and telecommunications volume per } \\
\text { capita (yuan/person) } \\
\text { Hospital bed capacity per 10,000 people (piece) } \\
\text { Boltzmann entropy of built-up land } \\
\text { The PAFRAC of built-up land } \\
\text { The CONTAG of built-up land } \\
\text { The COHESION of built-up land }\end{array}$ \\
\hline
\end{tabular}

\subsection{Change of URI Level}

The weight of URI indexes is calculated via the coefficient of variation $(\mathrm{C} \cdot \mathrm{V})(\mathrm{C} \cdot \mathrm{V}=$ (standard deviation /mean) $\times 100 \%$, and the change of weight of URI indexes in suburbs and exurbs of Chengdu from 2000 to 2015 is shown in Figure 8. First, the weight of social integration is the greatest, followed by economic integration, and the last is spatial integration. That indicates that economic integration and social integration has great significance in URI, and their effects are increasing year by year. The significance of spatial integration in URI has gradually reduced, which includes Boltzmann entropy, PAFRAC, CONTAG and the COHESION of built-up land. Second, among the economic integration indexes, the weights of per-capita disposable income of households, the proportion of primary industry in GDP, the proportion of tertiary industry in GDP, and the Engel coefficient are rising, while the percentages of the non-agricultural population, and the proportion of secondary industry in GDP are declining. This means that the impact of agriculture and services on URI is increasing, while the impact of household registration and industry is relenting. Third, among the social integration indexes, the weights of population migration rate, volume of passenger traffic, per-capita post, and telecommunications volume per capita are rising, which shows that the roles of population, logistics, and transportation in URI are growing; see Figure 8.

Based on factor weight results, the URI level in the suburbs and exurbs of Chengdu are obtained (Figure 9). Results show that URI levels in the suburbs and exurbs of Chengdu are higher than in western China, and there is a trend of steady improvement, but there is an imbalance in speed and region, which is consistent with previous studies of large cities in China [54]. One difference is that URI levels are generally high in China's eastern coastal cities, whereas there are large imbalances between regions in western China [55].

URI levels in the suburbs and exurbs of Chengdu rose from 2000 to 2015, more so in the suburbs than in the exurbs.

First, URI in the suburbs shows an obvious trend of integration in 2000. After that, URI in the suburbs steadily improved year by year, in particular in Xindu, Longquanyi, Wenjiang, Pidu, and Shuangliu. 


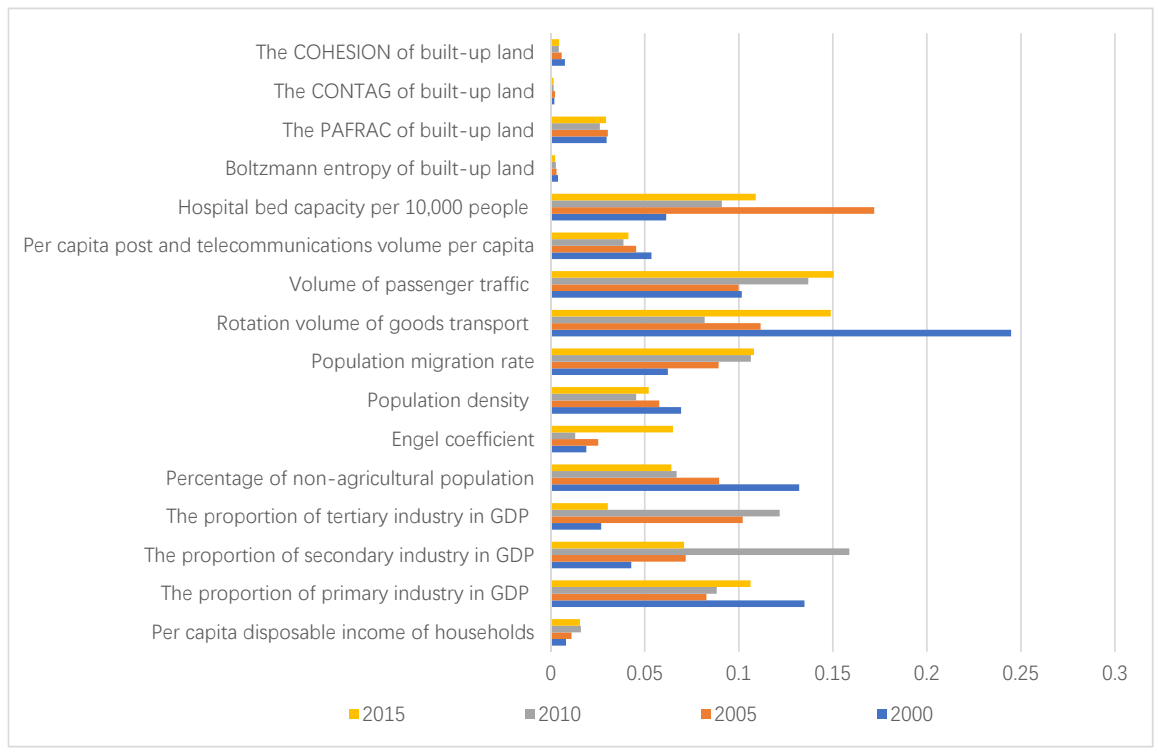

Figure 8. The change of weight of URI indexes from 2000 to 2015.
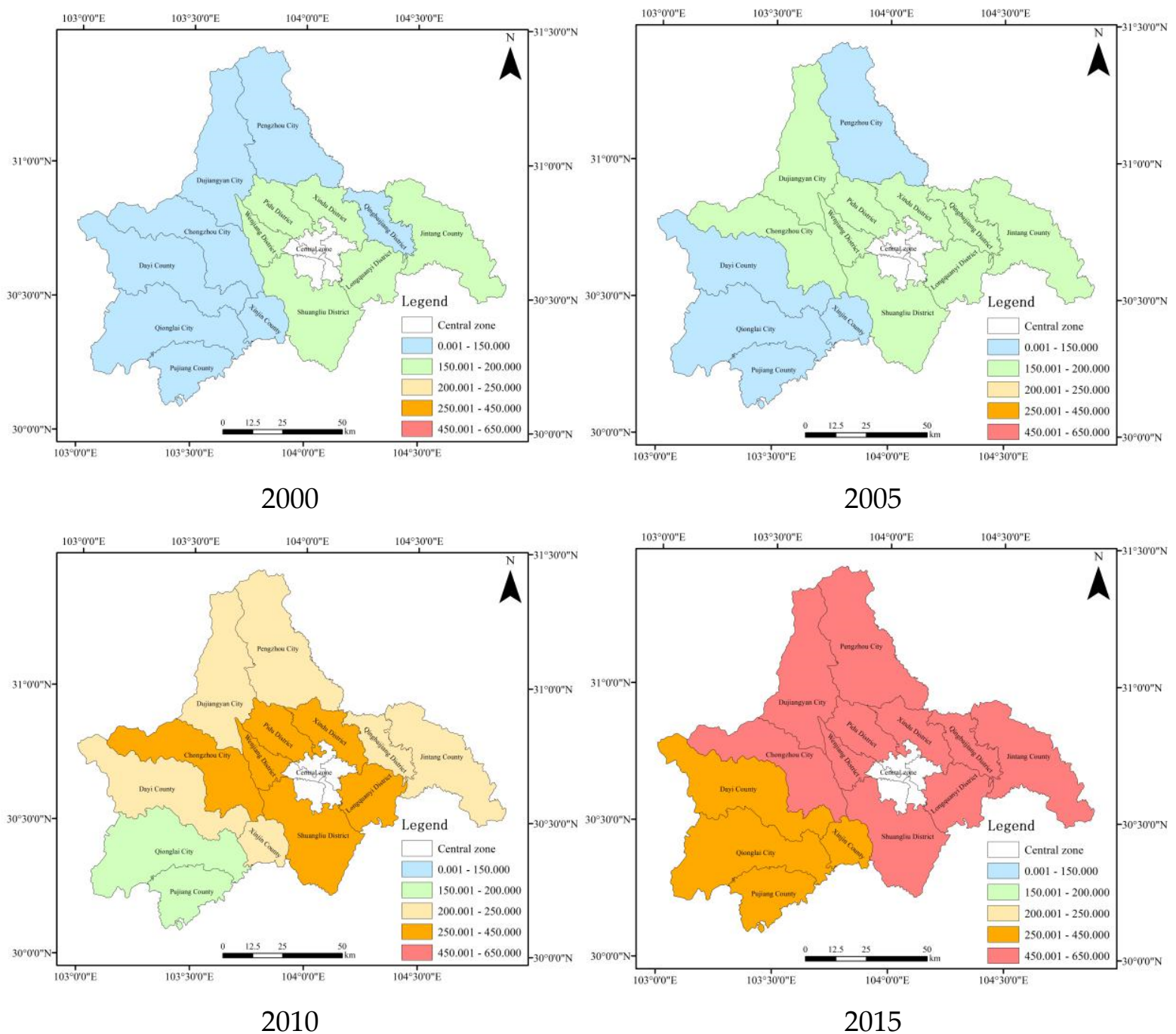

2010

Figure 9. The change of URI level from 2000 to 2015. 
Second, URI in the exurbs showed a marked difference. URI in the southeastern counties of the exurbs is generally high. Jintang has a clear trend towards URI in 2000, and after then its URI keeps pace with the suburbs, except for a small drop in 2010. However, it caught up with the suburbs regarding URI by 2015. The foundation of URI is weaker in the counties and districts in the southwestern exurbs in Chengdu, but they are growing steadily in URI. These are Dayi, Xinjin, Qionglai, and Pujiang. The northern counties in the exurbs of Chengdu are in the process of rapid URI; these counties are Pengzhou city, Dujiangyan city, and Chongzhou city.

Third, the speed of URI in the suburbs are higher, and counties in the suburbs have noticeably quickened their pace regarding URI since 2005. Meanwhile, the URI speed in the exurbs is generally slower.

\subsection{Path of URI}

The URI of Chengdu is guided by government, and originated in the land-owner contract pattern in Shuangliu in 2000 [56]. Under the guidance of the overall development of Chengdu, a series of measures were made to shorten the gaps between the central zone, suburbs, and exurbs. The goal is centralized improvements of industrial production and land use, as well as farmer identity change, becoming city-dwellers [57]. Through the integration of regional planning, industries, market systems, infrastructure, public services, and management systems [58], the four fundamental projects are concretely implemented: they are the rural property rights system reform, new rural grassroots governance mechanism construction, reform of village-level public services, and social management and comprehensive improvement to rural areas [59], which promotes the transformation of rural production and living as well as rural governance, making for all-round modernization in rural areas. Moreover, by supporting the functional reform of relevant governments, the endogenous driving force of urban and rural interactive development is formed, which makes for an integrated development pattern in Chengdu.

Considering the overall planning and integrated development of Chengdu since 2000, the paths of URI in the suburbs and exurbs are diverse. The URI in the suburbs mainly depends on the development of industry and the service industry, whereas the exurbs mainly depend on the development of agriculture, tourism, and infrastructure. In summary, there are five paths of URI in suburbs and exurbs in Chengdu.

First, the industry-developing model in suburbs: the most obvious example is Longquanyi, which vigorously developed secondary industry to build a strong industrial county in the suburbs, relying on favorable geographical advantages, high population density, and population migration rate. Meanwhile, the logistics industry developed. With that, the secondary industry and logistics industry promoted the rapid growth of the regional economy. It is worth noting that this is in contrast to the industry-developing model in Suzhou: by attracting foreign capital and developing an export-processing industry at the preliminary stage of industrialization [60], Suzhou has achieved industrial structure upgrading and capital accumulation, which has driven the development of local related enterprises. Chengdu is in the west of China. The overall economic development of western China is inferior to that of eastern China. The reality is that a high proportion of farmers and a prominent gap between urban and rural areas determines the suburbs of Chengdu, and it is impossible to adopt the same model of industrial expansion as is used with eastern coastal cities. Thus, the industry-developing model in the suburbs of Chengdu is developing advanced manufacturing, based on favorable conditions near Chengdu.

Second, the service-industry-developing model in suburbs: The most obvious example is Shuangliu, which developed tertiary industry and agriculture, relying on Shuangliu international airport and the economic and technological development zone southwest of the airport. In addition, using land resettlement compensation and land consolidation, it encourages farmers to live in towns, central villages, and settlement centers. These measures have proved effective in practice; using them, URI has been significantly accelerated, and people's living standards have been significantly improved. It has been documented 
that services have become and will continue to be the main channel for employment in large cities [61]; meanwhile, the organic integration of the producer service industry and manufacturing industry follows the trend of global industrial development, and is also an important way for China to take a new road to industrialization [61].

Third, the agriculture-developing model in the exurbs: The most obvious example is Dayi, which promotes modern agriculture to build strong agricultural counties in the exurbs, according to population advantage. In fact, it is feasible to develop agriculture in many cities in western China, because agriculture can raise farmer income and promote the development of an agricultural economy [62]. Furthermore, there is a large amount of arable land, and the limitation to developing agriculture is relatively light, so counties can improve labor productivity and increase output by developing large-scale and mechanized production [63], building a sound agricultural service system.

Fourth, the service-industry-developing model in the exurbs: The most obvious example is Dujiangyan, which propels URI by developing tourism and infrastructure with the advantage of rich tourism resources. Moreover, housing sites entering the market promote socio-economic development [64]. The Chaping village of Daguan town in Dujiangyan is the first village to embark on joint construction of housing sites in China, which allows farmers to co-build hotels on their homesteads, breaking the tradition that village hotels could only be built on state-owned land [65]. Practice indicates that housing sites entering the market is feasible- there are similar cases in Suzhou and Tianjin, the difference being that housing sites in Suzhou and Tianjin cannot be traded, and can only be swapped to local governments, not the individual [66].

Fifth, the infrastructure-developing model in the exurbs: A typical example is Qionglai. The hollowing out of the population and the absence of pillar industries are key problems [67], and the measures taken by Chengdu are extending social security coverage and building new houses in towns and cities to replace farmers' original homesteads, to attract farmers to live in towns or new communities under the premise of preventing rural hollowing out, which promotes farmers moving to cities, and creates conditions for large-scale land management at the same time. Furthermore, they improve infrastructure and public services in key towns and small cities, resulting in the carrying capacity and radiating capacity of towns increasing. In fact, Pengzhou, Chongzhou, and Qionglai are the epitomes of most counties in western China.

\section{Conclusions and Discussion}

Through a series of measures, URI of the suburbs and exurbs in Chengdu have achieved marked improvement. URI is the outcome of efficient policy and institutions and economic initiatives [68]. Suburbs and exurbs in Chengdu should continuously develop modern agriculture, industry, and service industries. First, stimulation is necessary of the independent development motivation of agriculture and farmers in rural areas. The focus of URI is the role of market mechanism [69], so Chengdu should enhance agricultural development and farmer production enthusiasm, which not only liberates rural production forces greatly, but also promotes the development of the rural economy. Second, further promotion of the urbanization process is necessary. In the coming years, it will be necessary to reform the household registration system continually. In addition, communication between the city and the country should be accelerated, which is the weak link in the URI of Chengdu, especially for counties in the exurbs [70]. Third, promotion of the integration of the three pillar industries and fostering of innovative mechanisms is necessary. The integration of these three industries is the foundation of URI for Chengdu [71]. Meanwhile, under the policy of rural revitalization, Chengdu should make great efforts to create effective institutions and mechanisms for URI, to build a comprehensive rural development system, and to promote the URI of the suburbs and exurbs in Chengdu. 
Author Contributions: M.W. and Y.Y. designed the experiments and wrote the paper; T.G. performed the experiments. All authors have read and agreed to the published version of the manuscript.

Funding: This research was funded by the fifth project of the second comprehensive scientific investigation on the Qinghai-Tibet Plateau (2019QZKK1005), the National Natural Science Foundation of China (41971198), Sichuan Science and Technology Program under Crant (2021YFG0028), and Chengdu Science and Technology Program under Grant (2019-YF05-01368-SN).

Institutional Review Board Statement: Not applicable.

Informed Consent Statement: Informed consent was obtained from all subjects involved in the study.

Conflicts of Interest: The author(s) declared no potential conflict of interests with respect to the authorship and/or publication of this article.

\section{References}

1. Liu, Y.S.; Li, Y.R. Revitalize the world's countryside. Nature 2017, 548, 275-277. [CrossRef]

2. Long, H.L.; Hu, Z.C.; Zou, J. The evolution of rural policy in Britain and its policy implications for rural development in China. Geogr. Res. 2010, 29, 1369-1378.

3. Dumbrell, J. The US-UK special relationship: Taking the 21st-century temperature. Br. J. Politics Int. Relat. 2009, 11, 64-78. [CrossRef]

4. Liu, Y.S. China's urban-rural integration and rural revitalization in the new era. Acta Geogr. Sin. 2018, 73, 637-650.

5. Yue, Z.; Li, S.; Feldman, M.W. Social Integration of Rural-Urban Migrants in China: Current Status, Determinants and Consequences; World Scientific: Singapore, 2015.

6. Liu, Y.; Long, H.; Chen, Y.; Wang, J.; Li, Y.; Li, Y.; Yang, Y.; Zhou, Y. Progress of research on urban-rural transformation and rural development in China in the past decade and future prospects. J. Geogr. Sci. 2016, 26, 1117-1132. [CrossRef]

7. Lu, Q.; Zhan, J.Y.; Lee, K.W. An overview on the urban-rural interaction in the past 50 years in China. Chin. Geogr. Sci. 2001, 11, 193-200. [CrossRef]

8. Yang, Z.H. The theoretical origin, connotation and mechanism analysis of URI development. Geogr. Geo-Inf. Sci. 2019, 35, 111-116.

9. Wang, X.Y.; Song, Y.; Song, F.H. New urbanization measurement and spatial differences in Shandong province. Sci. Geogr. Sin. 2014, 34, 1069-1076.

10. Zhou, K.; Song, L.Q. Research on the dynamic mechanism of institutional change of urban-rural integration in China. Contemp. Econ. Res. 2014, 12, 76-81.

11. Tang, Z.Q. Coupling study on the quality of rural migrant population and the carrying capacity of ecological environment in the transfer Area from the perspective of urban-rural integration. Agric. Econ. 2019, 4, 70-72.

12. Lu, D.D. Regional Development and Its Spatial Structure; Science Press: Beijing, China, 1995.

13. Wang, Y.; Fan, J. Spatial analysis of national-provincial pole-axis structure based on major function zoning in China. Geogr. Res. 2019, 38, 1651-1663.

14. Zhou, J.Y.; Bai, Y.X. The time series' fluctuation and regional difference of the urban-rural development integration level in china. China Ind. Econ. 2014, 2, 5-17.

15. Botturi, K.; Lacoeuille, Y.; Cavaillès, A.; Vervloet, D.; Magnan, A. Differences in allergen-induced cell activation between allergic asthma and rhinitis: Role of cd28, icos and ctla-4. Respir. Res. 2011, 12, 25. [CrossRef]

16. Xiu, C.L.; Xu, D.M.; Zhu, X.L. Evaluation of urban-rural integration course in Northeast China. Sci. Geogr. Sin. 2004, 24, 325-331.

17. Zhang, G.; Ji, L.Y.; Ma, J.W. The measurement and process comparison of urban-rural integration -evaluation of urban-rural integration in Beijing-Tianjin-Hebei region and Yangtze River Delta region. Econ. Probl. 2015, 36, 122-126.

18. Zhao, D.Q.; Chen, N. Research on the measurement of urban-rural integration development level in China. Explor. Econ. Probl. 2019, 12, 1-28.

19. Li, L.N.; Qu, L.1.; Liu, Y.S. Research on multi-body system identification method and its application in rural area. Geogr. Res. 2019, $38,563-577$.

20. McGee, T. Urbanisasi or kotadesasi? Evolving Pattern of Urbanization in Asia; University of Hawai Press: Honalulu, HI, USA, 1989.

21. Douglass, M. A regional network strategy for reciprocal rural-urban linkages: An agenda for policy research with reference to in donesia. Third World Plan. Rev. 1998, 20, 1-33. [CrossRef]

22. Carney, D. Sustainable Rural Livelihoods: What Contribution Can We Make? Universidad De Chile: Santiago, Chile, 1998.

23. Epstein, T.S.; Jezeph, D. Development-there is another way: A rural-urban partnership development paradigm. World Dev. 2001, 29, 1443-1454. [CrossRef]

24. Yao, S.M.; Fang, G.K.; Nipper, J. A comparative study on urban-rural integration between China and Germany-A case study of Yangtze Delta and the lower reaches of Rhine. Hum. Geogr. 2004, 2, 30-34.

25. Wang, T. A construction and empirical analysis on URI index system in Shanghai. J. Xidian Univ. 2014, $24,33-40$.

26. Zhong, S.C. A Study on the trend of technological progress and employment growth in China's manufacturing industry under openness. Econ. Surv. 2018, 35, 71-77.

27. Lens, M.C. The impact of housing vouchers on crime in US cities and suburbs. Urban Stud. 2014, 51, 1274-1289. [CrossRef] 
28. Goudie, D. Zonal method for urban travel surveys: Sustainability and sample distance from the CBD. J. Transp. Geogr. 2002, 10, 287-301. [CrossRef]

29. Wilson, J.; Spinney, J.; Millward, H.; Scott, D.; Hayden, A.; Tyedmers, P. Blame the exurbs, not the suburbs: Exploring the distribution of greenhouse gas emissions within a city region. Energy Policy 2013, 62, 1329-1335. [CrossRef]

30. Zhao, D.; Li, F.; Wang, R. Optimization of built-up land tructure based on ecological green equivalent: A case study in Ningguo city, China. Acta Ecol. Sin. 2011, 20, 35-46.

31. Tuan, Y.F. Topophilia: A Study of Environmental Perception; Columbia University Press: New York, NY, USA, 1990.

32. Gong, J.; Hu, Z.; Chen, W.; Liu, Y.; Wang, J. Urban expansion dynamics and modes in metropolitan Guangzhou, China. Land Use Policy 2018, 72, 100-109. [CrossRef]

33. Johnson, B.E.; Shifferd, J. Who lives where: A comprehensive population taxonomy of cities, suburbs, exurbs, and rural areas in the United States. Geogr. Bull. 2016, 57, 25-40.

34. Song, Z.J.; Yu, L.J. A study on the generalised space of urban-rural integration in Beijing suburbs during the present day. Urban Stud. 2015, 52, 2581-2598. [CrossRef]

35. Wei, J.; Yin, H.S. Evolution of agricultural structure and the limiting factors of intensive land use in the suburb of Jincheng city. J. Shanxi Agric. Sci. 2016, 44, 1899-1902.

36. Qing, Y.U.; Han, M. Construction and practical application of PMSI model for tourist traffic congestion in suburban scenic area: A case study of Yandangshan-Nanxijiang National Scenic Area. Geogr. Res. 2016, 35, 1589-1598.

37. Zhao, T.T.; Zhang, F.R.; Jiang, G.H. Interaction research on increase of urban built-up land and decrease of rural residential area in Shunyi district of Beijing city. Sci. Technol. Manag. Land Resour. 2008, 25, 11-17.

38. Krannich, R.S. Factors influencing farmers' expectations to sell agricultural land for non-agricultural uses. Rural Sociol. 2010, 67, 442-463.

39. Simmons, C.S.; Perz, S.; Pedlowski, M.A.; Silva, L.G.T. The changing dynamics of land conflict in the Brazilian Amazon: The rural-urban complex and its environmental implications. Urban Ecosyst. 2002, 6, 99-121. [CrossRef]

40. Jacob, B.; Mcmillen, D. Border effects in built-up land use. Natl. Tax J. 2015, 68, 855-874. [CrossRef]

41. Wang, K.; Xie, D.T.; Huang, C.F. Hook benefit evaluation on the increase of urban built-up land and the decrease of rural built-up land in the suburbs of Chongqing city, China. Asian Agric. Res. 2011, 3, 86-88.

42. Wei, Y.; Zhang, Z. Assessing the fragmentation of construction land in urban areas: An index method and case study in Shunde, China. Land Use Policy 2012, 29, 417-428. [CrossRef]

43. Du, S.; Shi, P.; Anton, V.R. The Relationship between Urban Sprawl and Farmland Displacement in the Pearl River Delta, China. Land 2013, 3, 34-51. [CrossRef]

44. Wei, Y.P.; Zhao, M. Urban spill over vs. local urban sprawl: Entangling landuse regulations in the urban growth of China's megacities. Land Use Policy 2009, 26, 1031-1045.

45. Jonida, B.D.; Zulkifli, A.; Matin, Q. Land-use change and income inequality in rural Indonesia. For. Policy Econ. 2018, 94, 55-66.

46. Tarasovičová, Z.; Saksa, M.; Blažík, T.; Falt'an, V. Changes in agricultural land use in the context of ongoing transformational processes in Slovakia. Agriculture 2013, 59, 49-64. [CrossRef]

47. Tian, X.; Zhou, S.; Wu, H. Study on Comprehensive Measurement and Spatial Difference of Land Use Fragment at County Level: A Case Study of Donghai County, Jiangsu Province. Resour. Environ. Yangtze River Basin 2013, 22, 1142-1148.

48. Gong, B.; Im, J.; Mountrakis, G. An artificial immune network approach to multi-sensor land use/land cover classification. Remote Sens. Environ. 2011, 15, 600-614. [CrossRef]

49. Gao, P.; Zhang, H.; Li, Z. An efficient analytical method for computing the Boltzmann entropy of a landscape gradient. Trans. Gis. 2018, 22, 1046-1063. [CrossRef]

50. Chen, Y. Derivation of the functional relations between fractal dimension of and shape indices of urban form. Comput. Environ. Urban Syst. 2011, 35, 442-451. [CrossRef]

51. Gao, P.; Zhang, H.; Wu, Z. Wasserstein metric-based Boltzmann entropy of a landscape mosaic: A clarification, correction, and evaluation of thermodynamic consistency. Landsc. Ecol. 2021, 36, 1-13. [CrossRef]

52. Dai, K.; Shen, S.; Cheng, C.; Ye, S.; Gao, P. Trade-off relationship of arable and ecological land in urban growth when altering urban form: A case Study of Shenzhen, China. Sustainability 2020, 12, 10041. [CrossRef]

53. Che, B.Q.; Lu, Y.Q.; Wang, Y. Research on spatial form evolution of urban and rural integration development in Jiangsu Province. Resour. Environ. Yangtze Basin 2017, 7, 70-79.

54. Cao, M.X.; Bao, Z.S. Calculation and analysis of Suzhou urban-rural integration. Res. Agric. Mod. 2010, 31, 451-454.

55. Guo, L.; Guo, J. The different development of URI in Western China. J. Xi'an Univ. Financ. Econ. 2019, 32, 62-68.

56. Ye, X. China's Urban-Rural Integration Policies. J. Curr. Chin. Aff. 2009, 38, 117-143. [CrossRef]

57. Zhou, X.Y. Research on "Chengdu Model" of URI; Southwest Jiaotong University: Chengdu, China, 2008.

58. Liu, S.L.; Qin, Y.Y. The internal logic and transmission path of the linkage between homestead transfer and peasant housing security under the background of peasant stratum differentiation. Rural Econ. 2020, 1, 32-38.

59. Li, G.Y. Chengdu model of balancing urban and rural development. Chin. J. Syst. Sci. 2010, 18, 67-71.

60. Li, G.; Wang, M.; Wu, J. A preliminary study on "Chengdu model" of overall planning for urban and rural development. J. Syst. Sci. 2010, 1, 69-73.

61. Shieh, L. Becoming urban: URI in Nanjing, Jiangsu province. Pac. Aff. 2011, 84, 475-494. [CrossRef] 
62. Duong, T.T.; Brewer, T.; Luck, J.; Zander, K. A global review of farmers' perceptions of agricultural risks and risk management strategies. Agriculture 2019, 9, 10. [CrossRef]

63. Mu, S.L.; Zhang, Y.F.; Wang, K.Y.; Bijaya, G.C.D. Agricultural pand contract and Management rights: Transferring price and countermeasures in typical agricultural areas of China. J. Resour. Ecol. 2012, 3, 262-268.

64. Yang, X.H.; Hong, G.W.; Zhao, J.F. Configuration of the public service facilities in Suzhou rural area on the background of the URI. Urban Plan. Forum 2013, 3, 22-27. [CrossRef]

65. Ling, Z.L.; Xiu, Z.W.; Ying, F. A study on household land transfer intention and its influencing factors in earthquake-stricken areas -A case study of Dujiangyan City. Rural Econ. 2012, 3, 14-18.

66. Yu, Z.; Wu, C.; Tan, Y.; Zhang, X. The dilemma of land expansion and governance in rural China: A comparative study based on three townships in Zhejiang Province. Land Use Policy 2018, 71, 602-611. [CrossRef]

67. Wu, J.L.; Chen, Y.R. Analysis on the problem of hollow village in China based on the land-use cost. Rural Econ. 2008, 4, 40-43.

68. Yao, S.R.; Zhou, Y.J. The market-driven mode and realization path of rural urbanization-A case study of Fuhong town, Chengdu. Rural Econ. 2018, 5, 81-86.

69. Chen, M.X. Exploration on the long-term mechanism of urban-rural integration development. Reg. Econ. Rev. 2018, 33, 125-127.

70. Song, H.Y. Accelerate the reform of rural household registration system to promote the integrated development of both urban and rural areas. Res. Agric. Mod. 2016, 37, 1021-1028.

71. Kassalis, I. Industrial clusters: An opportunity to stimulate business entities integration and competitiveness. Econ. Sci. Rural Dev. 2010, 23, 14-21. 